\title{
REVIEW
}

\section{Blast transformation and fibrotic progression in polycythemia vera and essential thrombocythemia: a literature review of incidence and risk factors}

\author{
S Cerquozzi and A Tefferi
}

Polycythemia vera (PV) and essential thrombocythemia (ET) constitute two of the three BCR-ABL1-negative myeloproliferative neoplasms and are characterized by relatively long median survivals (approximately 14 and 20 years, respectively). Potentially fatal disease complications in PV and ET include disease transformation into myelofibrosis (MF) or acute myeloid leukemia (AML). The range of reported frequencies for post-PV MF were $4.9-6 \%$ at 10 years and $6-14 \%$ at 15 years and for post-ET MF were $0.8-4.9 \%$ at 10 years and $4-11 \%$ at 15 years. The corresponding figures for post-PV AML were $2.3-14.4 \%$ at 10 years and $5.5-18.7 \%$ at 15 years and for post-ET AML were $0.7-3 \%$ at 10 years and $2.1-5.3 \%$ at 15 years. Risk factors cited for post-PV MF include advanced age, leukocytosis, reticulin fibrosis, splenomegaly and JAK2V617F allele burden and for post-ET MF include advanced age, leukocytosis, anemia, reticulin fibrosis, absence of JAK2V617F, use of anagrelide and presence of ASXL1 mutation. Risk factors for post-PV AML include advanced age, leukocytosis, reticulin fibrosis, splenomegaly, abnormal karyotype, TP53 or RUNX1 mutations as well as use of pipobroman, radiophosphorus $\left(\mathrm{P}^{32}\right)$ and busulfan and for post-ET AML include advanced age, leukocytosis, anemia, extreme thrombocytosis, thrombosis, reticulin fibrosis, TP53 or RUNX1 mutations. It is important to note that some of the aforementioned incidence figures and risk factor determinations are probably inaccurate and at times conflicting because of the retrospective nature of studies and the inadvertent labeling, in some studies, of patients with prefibrotic primary MF or 'masked' PV, as ET. Ultimately, transformation of MPN leads to poor outcomes and management remains challenging. Further understanding of the molecular events leading to disease transformation is being investigated.

Blood Cancer Journal (2015) 5, e366; doi:10.1038/bcj.2015.95; published online 13 November 2015

\section{INTRODUCTION}

Myeloproliferative neoplasms (MPN) are hematopoietic stem cell malignancies characterized by clonal proliferation of myeloidlineage cells. The four popular (also known as 'classic') MPN are chronic myeloid leukemia, polycythemia vera (PV), essential thrombocythemia (ET) and primary myelofibrosis (PMF). ${ }^{1} \mathrm{PV}, \mathrm{ET}$ and PMF are operationally referred to as $B C R-A B L 1$-negative MPN and are characterized by recurrent $J A K 2$, calreticulin $(C A L R)$ or myeloproliferative leukemia virus oncogene (MPL) mutations.

In a recently published study with mature survival data, lifeexpectancy was significantly compromised in all three BCR-ABL1negative MPN and median survivals for PV and ET were reported at approximately 14 and 20 years, respectively, and in those $<60$ years of age at 24 and 30 years. ${ }^{2}$ The International Working Group for MPN Research and Treatment (IWG-MRT) have identified thrombosis history, leukocytosis and advanced age as independent risk factors for overall survival in both PV and ET (Table 1). ${ }^{3,4}$ Disease-related complications affecting survival in both PV and ET include thrombohemorrhagic events and disease transformation into myelofibrosis (MF) or acute leukemia, also known as 'blast phase (BP)' disease. The latter is often in the form of acute myeloid leukemia (AML) although cases of lymphoblastic transformation have been reported. ${ }^{5-7}$ Post-MPN AML has dismal prognosis with median survival of $<6$ months and long-term remissions can only be achieved through allogeneic stem cell transplant. ${ }^{8,9}$ Here we review the reported rates of both fibrotic and leukemic transformation (LT) in PV and ET and the risk factors associated with disease progression.

\section{POST-POLYCYTHEMIA VERA MYELOFIBROSIS (POST-PV MF)}

Post-PV MF represents a natural evolution of PV and is defined based on IWG-MRT consensus criteria requiring a history of a World Health Organization (WHO)-diagnosed PV and bone marrow fibrosis grade $\geqslant 2$ ( 3 -point scale) or $\geqslant 3$ (4-point scale). At least two of the following features must also be present: anemia or sustained loss of need for phlebotomy and/or cytoreductive therapy, a leukoerythroblastic peripheral smear, splenomegaly and one or more constitutional symptoms. ${ }^{10}$ Less than $10 \%$ of PV patients evolve into MF within their first decade with reported incidences shown in Table 2 ranging from $2.3 \%$ to $23 \%$. ${ }^{2,3,7,11-20}$ The cumulative incidence of MF evolution is $5-14 \%$ at 15 years. $^{7,11,17}$ Interestingly, a recent cohort of Chinese PV patients demonstrated significantly higher 10-, 15- and 20-year incidences of post-PV MF at 27.4, 39.9 and $61.1 \%$, which may suggest that this population of patients are at higher risk of fibrotic transformation. ${ }^{20}$ Ultimately, transformation to MF shortens PV survival rates (hazards ratio $(\mathrm{HR})=2.17$; confidence interval $(\mathrm{Cl})$ : 1.27-3.72, $P=0.005)$, after adjusting for prognostic factors

Division of Hematology, Department of Medicine, Mayo Clinic, Rochester, MN, USA. Correspondence: Professor A Tefferi, Division of Hematology, Department of Medicine, Mayo Clinic, 200 First Street SW, Rochester, MN 55905, USA. 
Table 1. Predicting long-term outcomes for patients with polycythemia vera and essential thrombocythemia

\begin{tabular}{|c|c|c|}
\hline & PV & $E T$ \\
\hline Overall survival (years) & $13.5-24$ & $11-22.6$ \\
\hline \multirow{4}{*}{ Cumulative risks } & - & $0.2-0.3 \%$ at 5 years \\
\hline & $2.3-14.4 \%$ at 10 years & $0.7-3 \%$ at 10 years \\
\hline & $5.5-18.7 \%$ at 15 years & $2.1-5.3 \%$ at 15 years \\
\hline & $7.9-17 \%$ at 20 years & $8.1 \%$ at 20 years \\
\hline \multirow{4}{*}{ Cumulative risks } & - & $0.1-1 \%$ at 5 years \\
\hline & $4.9-6 \%$ at 10 years & $0.8-4.9 \%$ at 10 years \\
\hline & $6-14 \%$ at 15 years & $4-11 \%$ at 15 years \\
\hline & $26 \%$ at 20 years & $19.9 \%$ at 20 years \\
\hline Risk algorithms & IWG-MRT ${ }^{3}$ - to predict overall survival & $\begin{array}{l}\text { IPSET }^{4} \text { - to predict survival and } \\
\text { occurrence of thrombosis }\end{array}$ \\
\hline \multicolumn{3}{|l|}{ Risk factors } \\
\hline Thrombosis & Venous thrombosis (1 pt) & Yes (1 pt) \\
\hline \multicolumn{3}{|l|}{ Category } \\
\hline Low risk & 0 pts & $0 \mathrm{pts}$ \\
\hline Intermediate risk & $1-2$ pts & $1-2 \mathrm{pts}$ \\
\hline High risk & $\geqslant 3$ pts & $3-4$ pts \\
\hline \multicolumn{3}{|l|}{ Survival (years) } \\
\hline Low risk & 26 & NR \\
\hline Intermediate risk & 15 & 24.5 \\
\hline High risk & 8.3 & 13.8 \\
\hline
\end{tabular}

such as age, white blood cell count, hemoglobin level, platelet count and spleen size. ${ }^{21}$ Older age $(\geqslant 60$ years) and leukocytosis ( $>10$ or $15 \times 10^{9} / \mathrm{l}$ ) increases the risk for post-PV MF evolution. $^{14,21,22}$ Based on both retrospective and prospective studies, median time to MF transformation is $8.5-20$ years from time of diagnosis. $2,7,11,14,17-19 \mathrm{PV}$ patients $\leqslant 45$ years have a longer median time to MF transformation of 20 years compared with transforming in a median 8 years for patients who are $\geqslant 65$ years. ${ }^{18}$ In a large prospective multicentered cohort of 1638 PV patients, 38 (2\%) transformed to MF whereby greater duration of disease impacted transformation rates. PV patients with a disease course of 6-10 years had a relative risk of fibrotic transformation of $5.74 ; 95 \% \mathrm{Cl}, 1.51-21.77$ and while disease duration $>10$ years resulted in relative risk of $15.24 ; 95 \% \mathrm{Cl}, 4.22-55.06 ; P<0.0001 .{ }^{13}$ Additional risk factors for post-PV MF include: presence of baseline bone marrow fibrosis, JAK2V617 allele burden, splenomegaly, thrombocytosis (platelet count $>550 \times 10^{9} /$ l) and the presence of a 'masked PV' phenotype (display PV-characteristic BM morphology but lower hemoglobin levels than WHO criteria targets). ${ }^{15,16,20,23-25}$ Once transformed to post-PV MF, median survival is drastically shortened to 5.7 years. ${ }^{21}$ Passamonti et al. ${ }^{21}$ developed a dynamic prognostic model for patients who developed post-PV MF based on three independent risk factors: hemoglobin $<100 \mathrm{~g} / \mathrm{l}$, platelet count $<100 \times 10^{9} / \mathrm{l}$, and leukocyte count $>30 \times 10^{9} /$. The presence of any of these risk factors results in a 4.2-fold increased risk of death. Anemia, at the time of MF transformation, leads to significant differences in survival of 6.6 versus 1.9 years for patients with hemoglobin $\geqslant 100 \mathrm{~g} / \mathrm{l}$ compared with $<100 \mathrm{~g} / \mathrm{l}$, respectively $(P<0.001){ }^{21}$ Similarly, among a Chinese cohort, anemia (hemoglobin $<100 \mathrm{~g} / \mathrm{l}$ ) and age $>65$ years significantly predicted worse outcomes, resulting in a 5-year survival rate of only $17.3 \%$ (median 3 years) in post-PV MF patients with both risk factors. ${ }^{20}$

\section{POST-POLYCYTHEMIA VERA ACUTE MYELOID LEUKEMIA}

Based on large multicenter PV patient data, rates of LT in PV are estimated at $2.3 \%$ at 10 years, $5.5 \%$ at 15 years and remain $<10 \%$ at 20 years. ${ }^{2,3}$ Higher cumulative incidence rates or actuarial risks of LT of $8-14 \%$ at 10 years, $14-19 \%$ at 15 years and up to $24 \%$ at 18 years have been reported in smaller studies. ${ }^{7,17}$ As outlined in Table 2, LT typically occurs within a median time of 4.6-19 years from initial PV diagnosis. $2,3,7,11,12,14,17-19$ Younger patients $(\leqslant 45$ years) transform to leukemia at a median time of 19 years compared with 7 years for patients aged $>65$ years, but the difference is not statistically significant $(P=0.37)$. Rates of both MF and LT transformation occur at the same frequency between age groups (15\% versus 10\%, $P=0.29)$, although, as expected, leukemic development contributed to more deaths in older patients. ${ }^{18}$ Factors influencing leukemic-free survival included: age $\left(>61\right.$ years $^{3}$ or $\geqslant 70$ years), ${ }^{12,13}$ leukocytosis $\left(\geqslant 10 \times 10^{9} / \mathrm{l}\right.$ or $\left.\geqslant 15 \times 10^{9} / \mathrm{l}\right),{ }^{3,7,14}$ abnormal karyotype, ${ }^{3}$ splenomegaly, and bone marrow reticulin grade. ${ }^{16}$ In the two largest prospective studies including $>1500$ PV patients, age $>61$ years $(\mathrm{HR} 6.3 ; 95 \% \mathrm{Cl}$, $1.2-13.1, P=0.03)^{3}$ or $>70$ years (HR 4.30; $95 \% \mathrm{Cl}, 1.16-15.94$, $P=0.0294)^{12}$ and leukocytosis $\geqslant 15 \times 10^{9} / \mathrm{I}$ (HR of $3.9 ; 95 \% \mathrm{Cl}$, 1.3-11.6, $P=0.0004$ ) adversely impacted LT risk. ${ }^{3}$ Female sex was a risk factor in a single study by Finazzi et al. ${ }^{12}$ Lower cholesterol levels $(\leqslant 150 \mathrm{mg} / \mathrm{dl})$ has been linked to $\mathrm{AML} / \mathrm{myelodysplastic}$ syndrome (MDS) transformation (HR 6.58; 95\% Cl, 2.08-20.86, $P=0.0014$ ) and is seen in advanced stages of proliferative disease possibly representing a marker of disease activity. ${ }^{12,26}$ Multiple 


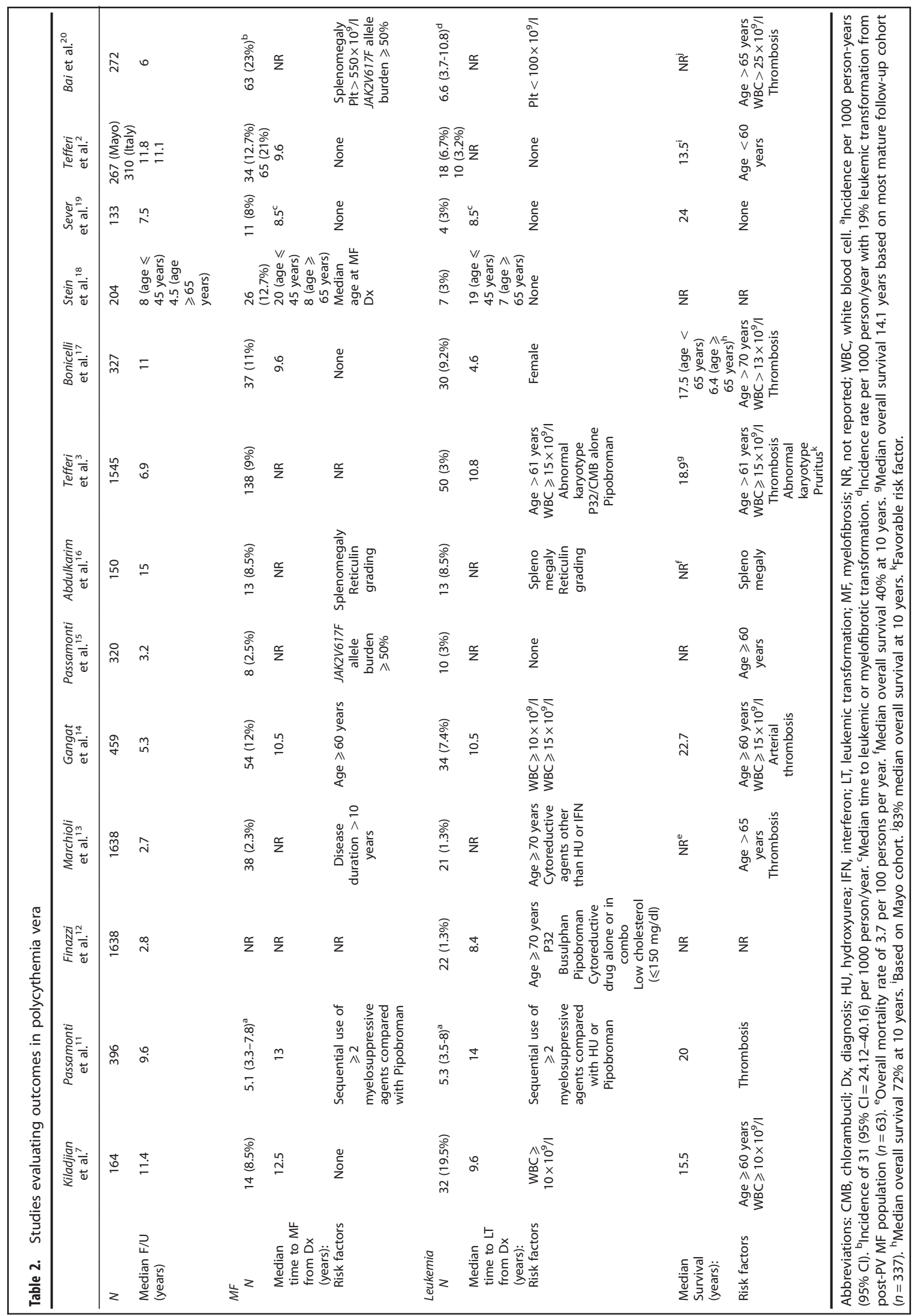


treatment regimens have also been linked to leukemic risk and will be discussed in greater detail below. Multivariate analysis has shown association of alkylating agents (pipobroman, $\mathrm{P}^{32}$, chlorambucil) and leukemia.,11-13 In particular, exposure to $P^{32}$, busulphan and pipobroman either alone or in combination has been linked to higher LT (HR of $5.46 ; 95 \% \mathrm{Cl}, 1.84-16.25$, $P=0.0023)$, with no LT risk associated with hydroxyurea (HU) usage alone (HR 0.86, 95\% Cl, 0.26-2.88, $P=0.8021) .{ }^{12} \mathrm{HU}$ remains a standard cytoreduction therapy in PV, and it is important to recognize that $\mathrm{HU}$ resistance increases both $\mathrm{LT}$ and MF transformation risk (HR 6.8; $95 \% \mathrm{Cl}, 3.0-15.4 \%, P<0.001$ ), whereas $\mathrm{HU}$ intolerance has no direct effect on outcomes. ${ }^{27}$

\section{POST-ESSENTIAL THROMBOCYTHEMIA MYELOFIBROSIS (POST-ET MF)}

Post-ET MF is defined based on IWG-MRT consensus criteria requiring a previously documented $\mathrm{WHO}$ diagnosis of ET and the presence of bone marrow fibrosis (grade $\geqslant 2$ on a 3-point scale or $\geqslant 3$ on a 4-point scale). Two or more additional features are needed, including: anemia (with $a \geqslant 2 \mathrm{mg} / \mathrm{l}$ decrease from baseline), leukoerythroblastic peripheral blood findings, splenomegaly, elevated lactate dehydrogenase and $\geqslant 1$ constitutional symptoms. ${ }^{10}$ Transformation to MF is less frequent in ET than PV and occurs late during the course of the disease. ${ }^{11,22,28}$ In larger cohort studies, the cumulative risk of post-ET MF is $3.9 \%$ at 10 years (incidence of $3.7 \times 1000$ person-years) and as high as $9.3 \%$ at 15 years. Table 3 summarizes rates of transformation among ET patients. Cumulative probabilities of fibrotic progression have been reported as $19.9 \%(5.6-12.6 \%)$ at 20 years. ${ }^{28}$ Overall, the median time to myelofibrotic transformation is approximately 7-16 years from time of ET diagnosis. ${ }^{1,28-33}$ The variation of cumulative incidence rates of transformation in ET are attributed to discrepancies in diagnosis, in particular, distinguishing between primary ET and prefibrotic MF. Barbui et al. ${ }^{34}$ compared the outcomes between confirmed ET and prefibrotic MF patients and identified that progression to overt MF at 10 and 15 years was $0.8 \%$ and $9.3 \%$, compared with $12.3 \%$ and $16.9 \%$, respectively. This correlates to a lower incidence of transformation of 0.5 per 100 patient-year in ET. ${ }^{34}$ Risk factors for MF transformation include: age, $^{34}$ anemia, ${ }^{16,22,30,34}$ and bone marrow histopathology, including hypercellularity and increased reticulin. ${ }^{16,33,34}$ The influence of molecular markers such as JAK2V617F will be discussed in detail below. Additional studies have found that increased serum lactate dehydrogenase, increased leukocytosis and male gender are risks for myelofibrotic transformation. ${ }^{16,30,33}$

\section{POST-ESSENTIAL THROMBOCYTHEMIA ACUTE MYELOID LEUKEMIA}

Earlier cohort studies of ET patients indicate that LT occurs at an incidence of $3 \times 1000$ person-years, with a cumulative risk of $2.6 \%$ at 10 years and $5.3 \%$ at 15 years. ${ }^{30}$ Higher rates of transformation have been found in French, Spanish and Chinese studies, with 10 -year rates of $8.3-9.7 \% .^{29,35,36}$ Conversely, much lower rates of $\mathrm{LT}$ have been identified as $<1 \%$ at 10 years and $2 \%$ in 15 years. ${ }^{11,34}$ Again, this variability in findings has largely been attributed to discrepancies in morphological diagnosis between ET and prefibrotic PMF related to modifications in the 2001 WHO classification of ET to prefibrotic MF. Accordingly, Barbui et al. ${ }^{34}$ confirmed ET in 891 patients based on the revised WHO criteria and found lower LT risks of $0.7 \%$ at 10 years and $2.1 \%$ at 15 years compared with $5.8 \%$ and $11.7 \%$ in the setting of early/prefibrotic PMF. In that particular study, prefibrotic PMF morphology, previous thrombosis and thrombocytosis $\left(>1000 \times 10^{9} / \mathrm{l}\right)$ were identified as risk factors. ${ }^{34}$ Other risk factors for LT include: leukocytosis $\left(\geqslant 15 \times 10^{9} / /\right),{ }_{16,29}^{16,22,37}$ extreme thrombocytosis $\left(\geqslant 1000 \times 10^{9} / \mathrm{l}\right),{ }^{34,37}$ anemia, ${ }^{16,22,37}$ older age $(\geqslant 60 \text { years })^{30,37}$ reticulin grading, and bone marrow cellularity. ${ }^{16,34}$ Among the Mayo clinic cohort of 605 ET patients, anemia ( $\mathrm{Hgb}<120 \mathrm{~g} / \mathrm{l}$ in females, $<135 \mathrm{~g} / \mathrm{l}$ in males) and thrombocytosis $\left(\geqslant 1000 \times 10^{9} / \mathrm{l}\right)$ were found to be significant risk factors, and when incorporated into a prognostic model, patients with no risk factors had a $0.4 \%$ versus $6.5 \%$ ( 2 risk factors) rate of $\mathrm{LT}(P=0.0009) .{ }^{37}$

\section{THERAPY-RELATED RISKS OF DISEASE TRANSFORMATION}

With the introduction of radiation treatment, in 1965, Modan and Lilienfeld observed that rates of PV-related LT were higher among X-ray-treated $(8.9 \%)$ and $\mathrm{P}^{32}$-treated $(11 \%)$ patients than the nonradiated $(1 \%)$ treatment groups. ${ }^{38}$ Both the Polycythemia Vera Study Group (PVSG) and the French Polycythemia Study Group (FPSG) have also illustrated the leukemogenic potential of $P^{32}$, with an incidence of $5-15 \%$ after 10 years of observation. ${ }^{38-40}$ In a large nested case-control study of MPN, AML/MDS development was significantly associated with $\mathrm{P}^{32}$ and alkylator exposure. ${ }^{41}$ Among alkylators, pipobroman has leukemogenic potential with actuarial leukemic risk of $14.4 \%$ and $18.7 \%$ at 10 and 15 years, respectively, reported among $164 \mathrm{PV}$ patients. ${ }^{7}$ When investigating the role of low-dose aspirin in PV patients, the use of $P^{32}$, pipobroman and busulphan independently had an impact on progression to AML/MDS in addition to the combination of either alkylating agent or $\mathrm{P}^{32}$ with $\mathrm{HU}$; however, the use of $\mathrm{HU}$ alone was not found to be leukemogenic (HR 0.86; 95\% Cl, 0.26-2.88, $P=0.8021) .^{12}$ The FPSG published their final results after a median follow-up of 16.3 years randomizing young PV patients $(<65$ years of age) to either first-line pipobroman or HU. In that study, the median survival was 17 years for the entire cohort compared with 20.3 years for those treated with $\mathrm{HU}$ and 15.4 years if received pipobroman $(P=0.008)$ and differed significantly from age- and sex-matched general population. The cumulative incidence of LT was $6.6,16.5$ and $24 \%$ in the $\mathrm{HU}$ arm versus 13 34 and $52 \%$ in the pipobroman arm $(P=0.004)$ at 10,15 and 20 years. This is despite patients being treated for longer durations in the HU arm (12 years) compared with pipobroman (9.5 years, $P<0.01$ ). When comparing single-agent therapy only (HU $n=94$, pipobroman $n=130$ ), the cumulative incidence of LT was $7.3,10.7$ and $16.6 \%$ compared with $14.6,34$ and $49.4 \%$ at 10,15 and 20 years, respectively $(P=0.002){ }^{42}$ This illustrates not only the leukemogenicity of pipobroman but also identifies the higher rates of LT with $\mathrm{HU}$ than previously reported in PV, which may or may not reflect the rate of natural evolution of the disease. In a large cohort of $>1500$ PV patients, multivariate analysis confirmed the association between LT and $\mathrm{P}^{32} /$ chlorambucil, pipobroman and pipobroman+HU/busulphan use. The use of $\mathrm{HU}$ or busulphan alone or in combination was not associated with leukemic risk. ${ }^{3}$ Likewise, cytoreductive agents unlike $\mathrm{HU}$ or interferon-alpha were associated with leukemic risk among the prospective multicenter PV study of 1638 patients. ${ }^{13}$ Although, HU treatment is not leukemogenic, therapy with $\geqslant 2$ cytoreductive treatments carries an increased risk of $\mathrm{LT}$ (odds ratio (OR) $2.9 ; 95 \% \mathrm{Cl}$, 1.4-5.9). ${ }^{41}$ It is important to consider the risks of additional therapy in the rare setting of $\mathrm{HU}$ intolerance or refractoriness when deciding on choices for alternative cytoreductive agents.

In contrast, the cumulative incidence of post-PV MF increases with $\mathrm{HU}$ at 15, 24 and $32 \%$ compared with 5, 10 and $21 \%$ using pipobroman $(P=0.02)$ at 10,15 , and 20 years, respectively. ${ }^{42}$ Accordingly, sequential use of two or more myelosuppressive agents leads to higher incidences of MF compared with pipobroman use alone. ${ }^{11}$ Although, PV patients receiving myelosuppressive agents had significantly higher MF transformation $(P=0.01)$, they also had a significantly longer follow-up period compared with those treated with phlebotomy alone $(P<0.001)$ and its was shown that longer follow-up also significantly led to higher rates of post-PV MF, thus making it difficult to conclude the effects of therapy on transformation. ${ }^{21}$ 


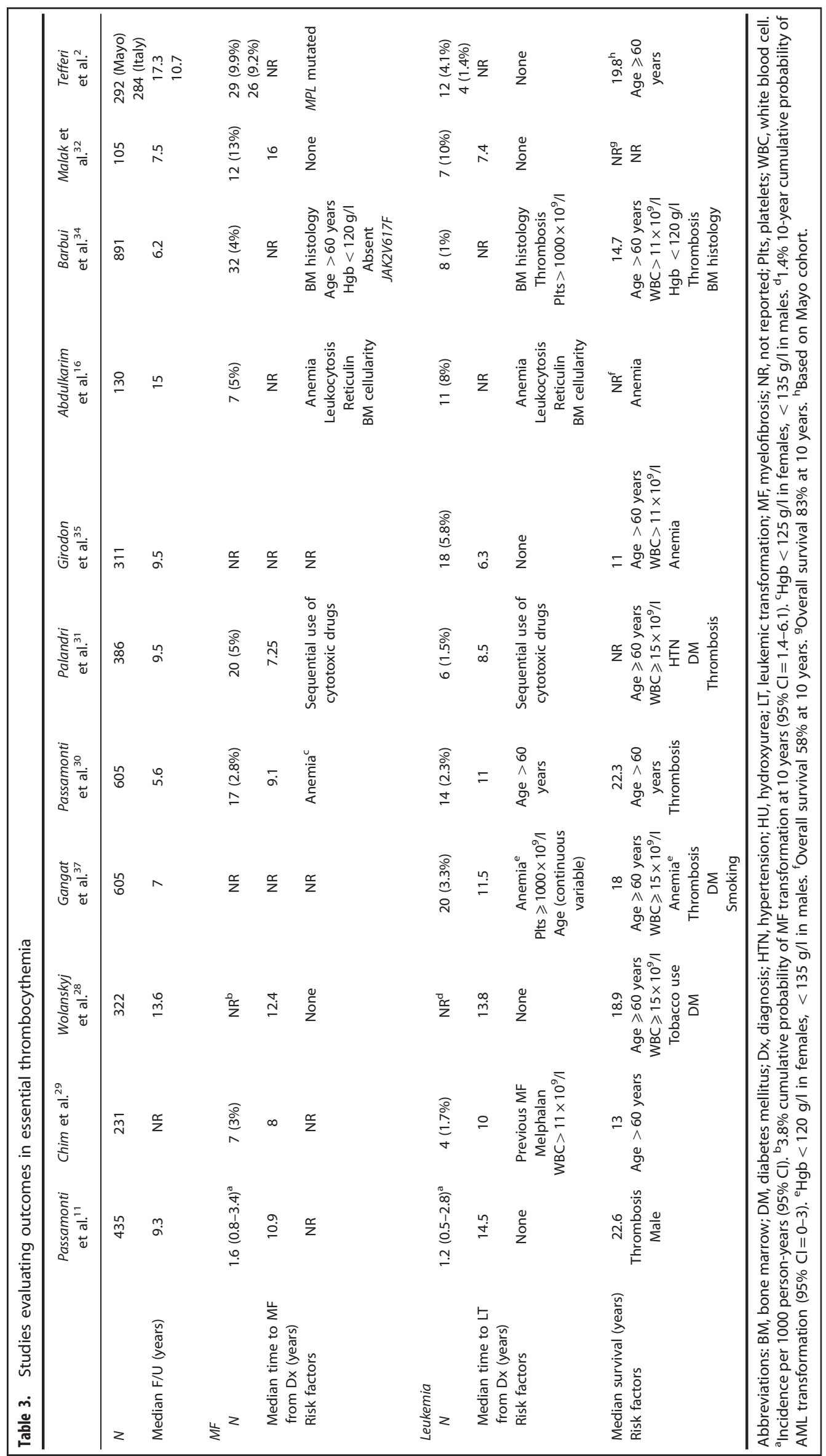


Few studies are available evaluating the efficacy and safety of cytoreductive agents in ET. Palandri et al. ${ }^{31}$ conducted a singleinstitution retrospective study on 386 ET patients with a median follow-up of 9.5 years (3-28.5 years) whereby $88 \%$ of the population received cytoreductive therapy. The evolution to $\mathrm{AML}$ and MF was $1.5 \%$ and $5 \%$, respectively, and transformation was not influenced by the type of cytoreductive therapy: HU or busulphan. However, patients receiving sequential therapy were at higher risk for AML/MDS compared with single-therapy use $(P=0.0039)$, and no disease transformation occurred among patients without treatment or if exposed to interferon alone. ${ }^{31}$ Anagrelide has been linked to post-ET MF, when compared with $\mathrm{HU}$ in the PT-1 trial and used in combination with aspirin (OR 2.92, $95 \% \mathrm{Cl}, 1.24-6.86, \quad P<0.01) .{ }^{43}$ Duration of anagrelide use (>60 months) posed a higher risk for transformation (OR 9.32; $95 \% \mathrm{Cl}, 1.1-78.5, P<0.01)^{44}$ However, no differences were found in the ANAHYDRET study that evaluated WHO-ET diagnosed patients compared with the UK-PT1 study, which based ET on PVSG criteria. ${ }^{45}$ Finally, melphalan exposure has been associated with increased risk of evolution to AML among ET patients although it is not a commonly used therapy. ${ }^{29}$

Overall, there is no confirmed consensus implicating $\mathrm{HU}$, anagrelide or busulphan as leukemogenic agents in PV or ET. The two largest non-controlled studies in $\mathrm{ET}^{37}$ and $\mathrm{PV}^{12}$ did not identify a risk of LT related to HU. Likewise, interferon-alpha has not been clearly implicated with transformation. ${ }^{31,46,47}$ The associations of higher transformation risk related to combination or sequential therapy are not clear and may be representative of more aggressive disease requiring more therapy with ultimately higher risk of progression. It is not well understood what influence chronic therapy has on the acquisition of genetic aberrations related to MPN and their associated risk to transformation. Genetic mutations leading to drug resistance may also have a role in disease transformation whereby the presence of $\mathrm{p} 53$ mutations may have suspected involvement in this process. ${ }^{48}$

\section{PROGNOSTIC IMPLICATIONS OF THE JAK2V617F MUTATION OR ITS ALLELE BURDEN}

Under normal circumstances, a polyclonal stem cell pool is responsible for hematopoiesis. In the setting of MPN, acquired mutations in hematopoietic stem cells lead to abnormal monoclonal or oligoclonal hematopoiesis. Additional genetic mutations may alter clinical phenotype pattern of each MPN, and during course of the disease, further genetic alterations can occur that promote disease progression and/or transformation. ${ }^{48} \mathrm{~A}$ major advance in understanding the pathogenesis of MPN was made with the discovery of the gain-of-function Janus kinase-2 (JAK2V167F) mutation in 2005. ${ }^{49-51}$ The most prevalent mutation in MPN is the JAK2V617F mutation on exon 14, which is present in $95 \%$ of PV and $50-60 \%$ of ET patients conferring a constitutive tyrosine kinase activity. ${ }^{49,50,52}$ Variable proportions of JAK2V617F mutant alleles are found in myeloid cell populations. ${ }^{53}$ The JAK2V617F mutation can be present in a heterozygous or a homozygous state, with the latter representing a mitotic recombination event resulting in uniparental disomy. ${ }^{54}$ Homozygosity is frequent in PV (25\%) that contributes to their higher mutant allele burden. ${ }^{54,55}$

A mutant allele dosage effect on clinical phenotype has been described in PV, whereby higher mutant allele burden correlates with higher severity of disease. ${ }^{55-57}$ Retrospective studies have identified that patients homozygous for JAK2V617F mutations are more likely to progress to post-PV MF. ${ }^{56-58}$ Rates of fibrotic transformation have been found to be $11.5 \%$ versus $1.4 \%{ }^{55}$ and $23 \%$ versus $2 \%{ }^{59}$ for homozygous compared with heterozygous JAK2 mutants, respectively. In a study of 647 patients, 68 evolved to post-PV MF, with $78 \%$ at the time of evolution having mutant allele burdens of $>50 \% .{ }^{21}$ Similarly, Passamonti et al. ${ }^{15}$ identified
320 PV patients (median follow-up of 3.2 years) in whom a mutant allele burden $\geqslant 50 \%$ was a significant risk factor for MF transformation. JAK2V617F allele burdens of $\geqslant 50 \%$ have been associated with elevated white blood cell $(P=0.034)$, thrombocytosis $(P=0.010)$ and, accordingly, higher incidence of both thrombosis $(P=0.032)$ and post-PV MF $(P=0.018) .^{20}$ Interestingly, in a study of $97 \mathrm{PV}$ patients, $21 \%$ had MF transformation, and $22 \%$ developed leukemia whereby JAK2V617F allele burden (>50\%) was associated with MF transformation $(P<0.0001)$ but not leukemogenesis. ${ }^{32}$ Higher JAK2V617F allele burdens of $>80 \%$ also correlated with advanced MF and greater splenomegaly. ${ }^{60}$ However, it should be noted that association of allelic burden and transformation, particularly risks of leukemic evolution, are not consistent in PV. ${ }^{19,61}$

Among ET patients, $14.3 \%$ of homozygous patients for the JAK2V617F mutation developed MF as compared with $4.7 \%$ of heterozygous patients $(P=0.011)$ or $1.6 \%$ of wild-type patients $(P=0.001) .^{57}$ In an evaluation of ET patients based on revised WHO criteria, Gangat et al. ${ }^{37}$ identified that the presence of JAK2V617F did not predict LT or inferior survival. In one of the largest ET studies comparing JAK2V617F mutated $(n=414)$ to unmutated cases $(n=362)$, there was no significant difference in survival, leukemic or MF transformation rates. ${ }^{62}$ Other studies confirmed the lack of correlation related to JAK2 mutational status and disease transformation. ${ }^{32,63,64}$ Interestingly, in a large multicenter study by Barbui et al. ${ }^{34}$ the presence of JAK2V617F mutation significantly decreased the rate of MF progression (HR $0.37 ; 95 \%$ $\mathrm{Cl}, 0.17-0.79, P=0.15)$ among ET patients but did not influence LT or overall survival. Finally, in comparing chronic phase to BP MPN, including both PV and ET, there was no statistical association between the time of LT or overall survival and JAK2V617F status. There is 20\% less incidence of JAK2V617F mutations in BP MPN versus chronic phase MPN. ${ }^{65}$ In fact, it is not uncommon to find isolated acute leukemic clones to have reverted to a JAK wild-type status at the time of transformation. ${ }^{66,67}$ Overall, JAK2V617F presence is not a prerequisite for LT and more likely additional genetic events are required in the setting of disease transformation. ${ }^{65}$

\section{MUTATIONS INFLUENCING DISEASE TRANSFORMATION}

Following the discovery of JAK2V617F mutation, additional somatic mutations have been found and implicated in MPN pathogenesis, particularly in cases of JAK2-negative disease (Table 4). MPL is found at chromosome 1 p34 and encodes the thrombopoietin receptor, which mediates signaling via the JAKSTAT (signal transducer and activator of transcription factor) pathway. MPL-acquired mutations (that is, W515L, W515K) occur in both ET and PMF, with approximately $1-4 \%$ in ET patients and mutually exclusive from JAK2V617F. ${ }^{68-70}$ Based on a population frequency of $6 \%$ in a MPN cohort study, MPL mutation status did not impact time to LT or overall survival. ${ }^{65}$ Additional studies have shown its lack of impact on post-ET MF or LT risk. ${ }^{69,70}$ In a longer follow-up study, higher rates of post-ET MF, leukemia and lower overall survival rates occurred in MPL-mutated ET $(3 \%, n=8)$ when compared with those with JAK2 or CALR mutations. ${ }^{71}$ CALR mutations are rare in PV but occur in approximately $15-32 \%{ }^{71-73}$ of ET cases, with higher incidences (49-71\%) in JAK2/MPL unmutated ET. ${ }^{72,74,75}$ CALR is located on chromosome $19 \mathrm{p} 13.2$ and is a multi-functional $\mathrm{Ca}^{2+}$-binding protein chaperone. ${ }^{76}$ In a recent follow-up study of 299 ET patients over 12.7 years, CALR mutations versus JAK2V617F mutations were associated with younger age $(P=0.002)$, male sex $(P=0.01)$, higher platelet count $(P=0.0004)$, lower hemoglobin $(P<0.0001)$, lower leukocytosis $(P=0.02)$ and lower thrombosis rates $(P=0.04)$. Between the two mutational groups, LT and myelofibrotic transformation rates were not significantly different $(P=0.28) .^{71}$ In other studies, the CALR mutation has been associated with decreased or equal incidence 
Table 4. Intrinsic risk factors for disease transformation in PV and ET

\begin{tabular}{lll}
\hline Transformation & Clinical risk factors & Genetic risk factors \\
\hline Post-PV MF & Age & JAK2V617F allele burden \\
& Leukocytosis & \\
& Disease duration & \\
& Reticulin fibrosis & \\
& Splenomegaly & \\
Post-PV Leukemia & Age & Abnormal karyotype \\
& Leukocytosis & TP53 \\
& Reticulin fibrosis & RUNX1 \\
& Splenomegaly & \\
& Age & Absent JAK2V617F mutation \\
Post-ET MF & Leukocytosis & ASXL1 \\
& Anemia & \\
& Reticulin fibrosis & \\
Post-ET leukemia & Age & TP53 \\
& Leukocytosis & RUNX1 \\
& Anemia & \\
& Reticulin fibrosis & \\
& Thrombosis & \\
& Platelets $\geqslant 1000 \times 10^{9} / 1$ &
\end{tabular}

Abbreviations: ET, essential thrombocythemia; MF, myelofibrosis; PV, polycythemia vera.

of $\mathrm{LT}^{73,77}$ with no clear association with post-ET MF. ${ }^{72,73}$ The role of $L N K(S H 2 B 3)$, an adaptor protein that is a negative regulator of thrombopoietin-MPL-mediated JAK activation pathway, is unclear. LNK mutations are associated with expansion of the myeloid progenitor precursors through the JAK-STAT pathway. In an analysis of 61 patients, LNK mutations were present in $9.8 \%$ of BP samples and were rare in chronic phase, suggesting that this mutation may be linked to leukemogenesis; however, they were not mutually exclusive of other MPN mutations and a direct genotype-phenotype correlation could not be concluded. ${ }^{78}$

Transcription factors have an important role in gene expression regulation and are often mutated in the setting of MPN. The gene encoding the lkaros transcription factor (IKZF1) was shown in MPN to be the target of chromosome 7p deletions, with loss of IKZFI associated with $\mathrm{LT}^{79}$ An important transcription factor that is responsible for cell cycle regulation and DNA damage response is p53 (encoded by TP53 gene), a tumor-suppressor protein that has been implicated in LT in MPN. ${ }^{80-82}$ Among 22 patients with postMPN AML, $45.5 \%$ had a form of $p 53$ mutation. ${ }^{82}$ In analyzing postMPN AML, the presence of p53 mutations was an adverse prognostic factor for overall survival (HR 2.67; 95\% Cl, $P=0.006) .{ }^{83}$ Likewise, the RUNX1/AML1 gene encodes a transcription factor involved in hematopoiesis, and mutations are linked to LT in MPNs. ${ }^{51,80,84}$ Finally, splicing factors have also been implicated with recurrent mutations in SRSF2, ZRSF2, U2AF1 and SF3B1 identified among 22 MPN patients with leukemia. ${ }^{85}$

In MPN-BP, genomic alterations are threefold $(P<0.001)$ more abundant compared with chronic phase. ${ }^{65}$ The spectrum of mutations in MPN-derived leukemia differs from de novo AML where in the latter we commonly see mutations in FLT3, NPM1 and DNMT3a. ${ }^{83,86,87}$ In post-MPN AML, gene sequencing studies have identified frequent mutations in epigenetic regulators such as teneleven translocation 2 (TET2), additional sex combs-like (ASXL1) and isocitrate dehydrogenase $(I D H 1 / 2)$ at the time of $\mathrm{LT}^{81,85,88,89}$ Rampal et al. ${ }^{81}$ identified additional mutations using highthroughput sequence analysis on post-MPN AML patients, including: CALR, MYC, PTPN11 and SETBP1. In JAK2V617F-mutated subgroups, common co-occurring mutations were TP53 (44\%), ASXL1 (44\%) and IDH2 (44\%), whereas CALR (43\%), ASXL1 (38\%) and SRSF2 tended to occur in JAK2 wild type post-MPN. TET enzymes catalyze conversion of 5-methylcytosine to 5-hydroxymethycytosine, which leads to DNA methylation. The frequency of TET2 mutations are $5 \%$ in ET and $16 \%$ in PV patients. ${ }^{90}$ The incidence of TET2 mutations in MPN-BP has been reported as $17 \%$, but the presence of the mutation among PV and PMF patients did not seem to affect LT or survival rates. ${ }^{90}$ The enzymes $I D H 1 / 2$ catalyze the conversion of isocitrate to alpha-ketoglutarate, which acts as a co-factor for TET2 whereby intact IDH activity is important for protection against oxidative stress. ${ }^{51}$ Mutations of IDH1 and IDH2 cause inhibition of TET2 activity, lead to decreased DNA methylation and impaired hematopoietic differentiation. ${ }^{91}$ There is a low incidence of IDH1/2 mutations in PV (1.9\%) and ET (0.8\%); however, in MPN-BP, IDH mutations are as high as $21.6 \%$, suggesting an association with $\mathrm{LT}(P<0.01)$ and confer a worse survival $(P=0.01) .{ }^{92}$ Finally, $A S X L 1$ is a nuclear polycomb protein with mutations found on chromosome 20q1.1 that affect the regulation of transcription and RAR-mediated signaling. ASXL1 mutations are rare in ET and PV but are most frequently found in post-ET MF and may be related to its pathogenesis. ${ }^{93}$

\section{CYTOGENETIC RISK FACTORS}

It is anticipated that our expanding knowledge of the genetic profiles of MPN will have an important role in predicting disease outcomes. Tefferi et al. $^{3}$ showed for the first time the prognostic relevance of karyotype in an international PV study. Similarly, Dingli et al. ${ }^{94}$ illustrated that cytogenetic findings likely superseded disease-related characteristics such as age and anemia for predicting survival among PV and ET patients with secondary MF. Frequently reported karyotype abnormalities in MPN-BP are complex often involving chromosomes 1, 9, 5 and 7 abnormalities. $8,19,84,95,96$ In general, cytogenetic abnormalities are estimated in $15 \%$ of PV patients. ${ }^{19,61}$ Among transformed PV patients, with no prior treatment exposures aside from phlebotomy, the most frequent cytogenetic abnormalities included: $+1 \mathrm{q}$, $+8,+9$, and $20 \mathrm{q}-.^{96}$ In ET, most patients have a normal karyotype at the time of diagnosis, with an overall prevalence of cytogenetic anomalies being $<10 \% .{ }^{97-99}$ Despite having abnormal cytogenetics at the time of diagnosis, ET patients do not have shorter survival or higher risks of myelofibrotic transformation or LT. ${ }^{97} \mathrm{At}$ the time of LT, most patients have a detectable abnormality. ${ }^{97,98,100}$ Overall, single-nucleotide polymorphism arrays have identified changes of chromosomes $1 q, 7 q, 5 q, 6 p$, $7 p, 16 q, 19 q, 21 q, 22 q$ and $3 q$ associated with post-MPN AML. ${ }^{65,84}$ High-resolution single-nucleotide polymorphism arrays have identified established targets relating to disease progression that include: MYC (chromosome 8), ETV6 (chromosome 12), TP53 (chromosome 17), and RUNX1 (chromosome 21). ${ }^{65,84}$ Clearly, in other myeloid malignancies and in primary MF, cytogenetics has an important role in prognosis, and currently our knowledge of its implication in PV and ET is expanding. Ultimately, with new technologic advancements, identifying candidate genes involved in transformation of both PV and ET into MF and AML/MDS can provide insight into the complex pathogenesis of MPN and assist in the development of therapeutic targets for prevention of transformation.

\section{CONCLUSION}

Both PV and ET are BCR-ABL1-negative MPN with increased morbidity and mortality mainly attributed to thrombohemorrhagic complications with progression to $\mathrm{AML}$ and MF leading to a dismal prognosis, particularly in the setting of LT where median survival is significantly shortened to $<6$ months. Allogeneic stem cell transplantation remains the only curative option in few eligible patients and new therapeutic agents remain in development. The underlying mechanism for transformation to either MF or $\mathrm{BP}$ remains unclear and is likely multifactorial. There is a need to 
improve the identification of high-risk patients. Understanding the genetic mutations that lead to disease progression and transformation is a current research focus, and with advancements in genetic profiling, the pathogenesis of MPN will become even more complex. It is anticipated that establishing genetic profiles within MPN will allow better classification of patients to improve clinical management and treatment.

\section{CONFLICT OF INTEREST}

The authors declare no conflict of interest.

\section{AUTHOR CONTRIBUTIONS}

SC and AT conceived and designed the work that led to submission. SC drafted the initial manuscript. SC and AT both edited and approved the final version of the manuscript.

\section{REFERENCES}

1 Spivak JL. The chronic myeloproliferative disorders: clonality and clinical heterogeneity. Semin Hematol 2004; 41: 1-5.

2 Tefferi A, Guglielmelli P, Larson DR, Finke C, Wassie EA, Pieri L et al. Long-term survival and blast transformation in molecularly annotated essential thrombocythemia, polycythemia vera, and myelofibrosis. Blood 2014; 124: 2507-2513.

3 Tefferi A, Rumi E, Finazzi G, Gisslinger H, Vannucchi A, Rodeghiero F et al. Survival and prognosis among 1545 patients with contemporary polycythemia vera: an international study. Leukemia 2013; 27: 1874-1881.

4 Passamonti F, Thiele JJ, Girodon F, Rumi E, Carobbio A, Gisslinger H et al. A prognostic model to predict survival in 867 World Health Organization defined essential thrombocythemia at diagnosis: a study by the International Working Group on Myelofibrosis Research and Treatment. Blood 2012; 120: 1197-1201.

5 Dunphy $\mathrm{CH}$, Kitchen S, Saravia O, Velasquez WS. Acute myelofibrosis terminating in acute lymphoblastic leukemia: case report and review of the literature. Am J Hematol 1996; 51: 85-89.

6 Polliack A, Prokocimer M, Matzner Y. Lymphoblastic leukemic transformation (lymphoblastic crisis) in myelofibrosis and myeloid metaplasia. Am J Hematol 1980; 9: 211-220.

7 Kiladjian J-J, Gardin C, Renoux M, Bruno F, Bernard J-F. Long-term outcomes of polycythemia vera patients treated with pipobroman as initial therapy. Hematol J 2003; 4: 198-207.

8 Tam CS, Nussenzveig RM, Popat U, Bueso-Ramos CE, Deborah A, Cortes JA et al. The natural history and treatment outcome of blast phase BCR-ABL myeloproliferative neoplasms. Blood 2008; 112: 1628-1637.

9 Kennedy JA, Atenafu EG, Messner HA, Craddock KJ, Brandwein JM, Lipton JH et al. Treatment outcomes following leukemic transformation in Philadelphianegative myeloproliferative neoplasms. Blood 2013; 121: 2725-2733.

10 Barosi G, Mesa RA, Thiele J, Cervantes F, Campbell PJ, Verstovsek S et al. Proposed criteria for the diagnosis of post-polycythemia vera and post-essential thrombocythemia myelofibrosis: a consensus statement from the International Working Group for Myelofibrosis Research and Treatment. Leukemia 2008; 22: 437-438.

11 Passamonti F, Rumi E, Pungolino E, Malabarba L, Bertazzoni P, Valentini M et al. Life expectancy and prognostic factors for survival in patients with polycythemia vera and essential thrombocythemia. Am J Med 2004; 117: 755-761.

12 Finazzi G, Caruso V, Marchioli R, Capnist G, Chisesi T, Finelli C et al. Acute leukemia in polycythemia vera: an analysis of 1638 patients enrolled in a prospective observational study. Blood 2005; 105: 2664-2670.

13 Marchioli R, Finazzi G, Landolfi R, Kutti J, Gisslinger H, Patrono C et al. Vascular and neoplastic risk in a large cohort of patients with polycythemia vera. J Clin Oncol 2005; 23: 2224-2232.

14 Gangat N, Strand J, Li CY, Wu W, Pardanani A, Tefferi A. Leucocytosis in polycythaemia vera predicts both inferior survival and leukaemic transformation. $\mathrm{Br} J$ Haematol 2007; 138: 354-358.

15 Passamonti F, Rumi E, Pietra D, Elena C, Boveri E, Arcaini $L$ et al. A prospective study of 338 patients with polycythemia vera: the impact of JAK2 (V617F) allele burden and leukocytosis on fibrotic or leukemic disease transformation and vascular complications. Leukemia 2010; 24: 1574-1579.

16 Abdulkarim K, Ridell B, Johansson $\mathrm{P}$, Kutti J, Safai-Kutti S, Andréasson B. The impact of peripheral blood values and bone marrow findings on prognosis for patients with essential thrombocythemia and polycythemia vera. Eur J Haematol 2010; 86: 148-155.
17 Bonicelli G, Abdulkarim K, Mounier M, Johansson P, Rossi C, Jooste V et al. Leucocytosis and thrombosis at diagnosis are associated with poor survival in polycythaemia vera: a population-based study of 327 patients. $\mathrm{Br} J$ Haematol 2013; 160: 251-254.

18 Stein BL, Saraf S, Sobol U, Halpern A, Shammo J, Rondelli D et al. Age-related differences in disease characteristics and clinical outcomes in polycythemia vera. Leuk Lymphoma 2013; 54: 1989-1995.

19 Sever M, Quintás-Cardama A, Pierce S, Zhou L, Kantarjian H, Verstovsek S. Significance of cytogenetic abnormalities in patients with polycythemia vera. Leuk Lymphoma 2013; 54: 2667-2670.

20 Bai J, Ai L, Zhang L, Yang F, Zhou Y, Xue Y. Incidence and risk factors for myelofibrotic transformation among 272 Chinese patients with JAK2-mutated polycythemia vera. Am J Hematol 2015; e-pub ahead of print 15 September 2015; doi:10.1002/ajh.24191.

21 Passamonti F, Rumi E, Caramella M, Elena C, Arcaini L, Boveri E et al. A dynamic prognostic model to predict survival in post-polycythemia vera myelofibrosis. Blood 2008; 111: 3383-3387.

22 Tefferi A, Gangat N, Wolanskyj AP, Schwager S, Pardanani A, Lasho TL et al. $20+y r$ without leukemic or fibrotic transformation in essential thrombocythemia or polycythemia vera: predictors at diagnosis. Eur J Haematol 2008; 80: 386-390.

23 Barbui T, Thiele J, Gisslinger H, Finazzi G, Carobbio A, Rumi E et al. Masked polycythemia Vera (mPV): results of an international study. Am J Hematol 2014; 89: $52-54$.

24 Tiribelli M, Barraco D, De Marchi F, Marin L, Medeot M, Damiani D. Clinical factors predictive of myelofibrotic evolution in patients with polycythemia vera. Ann Hematol 2014; 12: 14-15.

25 Barbui T, Thiele J, Passamonti F, Rumi E, Boveri E, Randi ML et al. Initial bone marrow reticulin fibrosis in polycythemia vera exerts an impact on clinical outcome. Blood 2012; 119: 2239-2241.

26 Finazzi G, Ruggeri M, Rodeghiero F, Barbui T. Second malignancies in patients with essential thrombocythaemia treated with busulphan and hydroxyurea: long-term follow-up of a randomized clinical trial. Br J Haematol 2000; 110: 577-583.

27 Alvarez-Larrán A, Pereira A, Cervantes F, Arellano-Rodrigo E, Hernández-Boluda $J C$, Ferrer-Marín $\mathrm{F}$ et al. Assessment and prognostic value of the European Leukemia Net criteria for clinicohematologic response, resistance, and intolerance to hydroxyurea in polycythemia vera. Blood 2012; 119: 1363-1369.

28 Wolanskyj AP, Schwager SM, McClure RF, Larson DR, Tefferi A. Essential thrombocythemia beyond the first decade: life expectancy, long-term complication rates, and prognostic factors. Mayo Clin Proc 2006; 81: 159-166.

29 Chim C-S, Kwong Y-L, Kwok-Wei A, Ma S-K, Chan C-C, Wong L-G et al. Long-term outcome of 231 patients with essential thrombocythemia: prognostic factors for thrombosis, bleeding, myelofibrosis, and leukemia. Arch Intern Med 2005; 165: 2651-2658.

30 Passamonti F, Rumi E, Arcaini L, Boveri E, Elena C, Pietra D et al. Prognostic factors for thrombosis, myelofibrosis, and leukemia in essential thrombocythemia: a study of 605 patients. Haematologica 2008; 93: 1645-1651.

31 Palandri F, Catani L, Testoni N, Ottaviani E, Polverelli N, Fiacchini M et al. Long term follow-up of 386 consecutive patients with essential thrombocythemia: safety of cytoreductive therapy. Am J Hematol 2009; 84: 215-220.

32 Malak S, Labopin M, Saint-Martin C, Bellanne-Chantelot C, Najman A. Long term follow up of 93 families with myeloproliferative neoplasms: life expectancy and implications of JAK2V617F in the occurrence of complications. Blood Cells Mol Dis 2012; 49: 170-176.

33 Alvarez-Larrán A, Cervantes F, Bellosillo B, Giralt M, Juliá A, Hernández-Boluda JC et al. Essential thrombocythemia in young individuals: frequency and risk factors for vascular events and evolution to myelofibrosis in 126 patients. Leukemia 2007; 21: 1218-1223.

34 Barbui T, Thiele J, Passamonti F, Rumi E, Boveri E, Ruggeri M et al. Survival and disease progression in essential thrombocythemia are significantly influenced by accurate morphologic diagnosis: an international study. J Clin Oncol 2011; 29: 3179-3184.

35 Girodon F, Dutrillaux F, Broséus J, Mounier M, Goussot V, Bardonnaud P et al. Leukocytosis is associated with poor survival but not with increased risk of thrombosis in essential thrombocythemia: a population-based study of 311 patients. Leukemia 2010; 24: 900-903.

36 Cervantes F, Alvarez-Larrán A, Talarn C, Gómez M, Montserrat E. Myelofibrosis with myeloid metaplasia following essential thrombocythaemia: actuarial probability, presenting characteristics and evolution in a series of 195 patients. Br J Haematol 2002; 118: 786-790.

37 Gangat N, Wolanskyj AP, McClure RF, Li C-Y, Schwager S, Wu W et al. Risk stratification for survival and leukemic transformation in essential thrombocythemia: a single institutional study of 605 patients. Leukemia 2007; 21: 270-276. 
38 Björkholm M, Hultcrantz M, Derolf ÅR. Leukemic transformation in myeloproliferative neoplasms: therapy-related or unrelated? Best Pract Res Clin Haematol 2014; 27: 141-153.

39 Berk PD, Goldberg JD, Silverstein MN, Weinfeld A, Donovan PB, Ellis JT et al. Increased incidence of acute leukemia in polycythemia vera associated with chlorambucil therapy. N Engl J Med 1981; 304: 441-447.

40 Najean Y, Rain JD. Treatment of polycythemia vera: use of $32 \mathrm{P}$ alone or in combination with maintenance therapy using hydroxyurea in 461 patients greater than 65 years of age. Blood 1997; 89: 2319-2327.

41 Björkholm M, Derolf AR, Hultcrantz M, Kristinsson SY, Ekstrand C, Goldin LR et al. Treatment-related risk factors for transformation to acute myeloid leukemia and myelodysplastic syndromes in myeloproliferative neoplasms. J Clin Oncol 2011; 29: 2410-2415.

42 Kiladjian JJ, Chevret S, Dosquet C, Chomienne C, Rain JD. Treatment of polycythemia vera with hydroxyurea and pipobroman: final results of a randomized trial initiated in. 1980J Clin Oncol 2011; 29: 3907-3913.

43 Harrison CN, Campbell PJ, Buck G, Wheatley K, East CL, Bareford D et al. Hydroxyurea compared with anagrelide in high-risk essential thrombocythemia. N Engl J Med 2005; 353: 33-45.

44 Mela Osorio MJ, Ferrari L, Goette NP, Gutierrez MI, Glembotsky AC, Maldonado $\mathrm{AC}$ et al. Long-term follow-up of essential thrombocythemia patients treated with anagrelide: subgroup analysis according to JAK2/CALR/MPL mutational status. Eur J Haematol 2015; e-pub ahead of print 19 July 2015; doi:10.1111/ejh.12614.

45 Gisslinger H, Gotic M, Holowiecki J, Penka M, Thiele J, Kralovics R et al. Anagrelide compared with hydroxyurea in WHO-classified essential thrombocythemia: the ANAHYDRET Study, a randomized controlled trial. Blood 2013; 121: 1720-1728.

46 Fruchtman SM, Petitt RM, Gilbert HS, Fiddler G, Lyne AAnagrelide Study Group. Analysis of long-term efficacy, safety and leukemogenic potential in myeloproliferative disorders. Leuk Res 2005; 29: 481-491.

47 Gowin K, Thapaliy P, Samuelson J, Harrison C, Radia D, Andreasson B et al. Experience with pegylated interferon $a-2 a$ in advanced myeloproliferative neoplasms in an international cohort of 118 patients. Haematologica 2012; 97: 1570-1573.

48 Them NCC, Kralovics R. Genetic basis of MPN: beyond JAK2-V617F. Curr Hematol Malig Rep 2013; 8: 299-306.

49 Kralovics R, Passamonti F, Buser AS, Teo S-S, Tiedt R, Passweg JR et al. A gain-offunction mutation of JAK2 in myeloproliferative disorders. N Engl J Med 2005; 352: 1779-1790.

50 James C, Ugo V, Le Couédic J-P, Staerk J, Delhommeau F, Lacout C et al. A unique clonal JAK2 mutation leading to constitutive signalling causes polycythaemia vera. Nature 2005; 434: 1144-1148.

51 Vainchenker W, Delhommeau F, Constantinescu SN, Bernard OA. New mutations and pathogenesis of myeloproliferative neoplasms. Blood 2011; 118: 1723-1735.

52 Baxter EJ, Scott LM, Campbell PJ, East C, Fourouclas N, Swanton S et al. Acquired mutation of the tyrosine kinase JAK2 in human myeloproliferative disorders. Lancet 2005; 365: 1054-1061.

53 Passamonti F, Rumi E, Pietra D, Della Porta MG, Boveri E, Pascutto C et al. Relation between JAK2 (V617F) mutation status, granulocyte activation, and constitutive mobilization of CD34+ cells into peripheral blood in myeloproliferative disorders. Blood 2006; 107: 3676-3682.

54 Alshemmari SH, Rajaan R, Ameen R, Al-Drees MA, Almosailleakh MR. JAK2V617F allele burden in patients with myeloproliferative neoplasms. Ann Hematol 2014; 93: 791-796.

55 Vannucchi A, Antonioli E, Guglielmelli P, Longo G, Pancrazzi A, Ponziani V et al. Prospective identification of high-risk polycythemia vera patients based on JAK2 (V617F) allele burden. Leukemia 2007; 21: 1952-1959.

56 Tefferi A, Lasho TL, Schwager SM, Strand JS, Elliott M, Mesa R et al. The clinical phenotype of wild-type, heterozygous, and homozygous JAK2 V617F in polycythemia vera. Cancer 2006; 106: 631-635.

57 Vannucchi AM, Antonioli E, Guglielmelli P, Rambaldi A, Marchioli R, Marfisi RM et al. Clinical profile of homozygous JAK2617V $>\mathrm{F}$ mutation in patients with polycythemia vera or essential thrombocythemia. Blood 2007; 110: 840-846.

58 Alvarez-Larrán A, Bellosillo B, Martínez-Avilés L, Saumell S, Salar A, Abella E et al. Postpolycythaemic myelofibrosis: frequency and risk factors for this complication in 116 patients. Br J Haematol 2009; 146: 504-509.

59 Tefferi A, Strand JJ, Lasho TL, Knudson RA, Finke CM, Gangat N et al. Bone marrow JAK2V617F allele burden and clinical correlates in polycythemia vera. Leukemia 2007; 21: 2074-2075.

60 Silver RT, Vandris K, Wang YL, Adriano F, Jones AV, Christos PJ et al. JAK2V617F allele burden in polycythemia vera correlates with grade of myelofibrosis, but is not substantially affected by therapy. Leuk Res 2011; 35: 177-182.

61 Gangat N, Strand J, Lasho TL, Finke CM, Knudson RA, Pardanani A et al. Cytogenetic studies at diagnosis in polycythemia vera: clinical and JAK2V617F allele burden correlates. Eur J Haematol 2008; 80: 197-200.
62 Campbell PJ, Scott LM, Buck G, Wheatley K, East CL, Marsden JT et al. Definition of subtypes of essential thrombocythaemia and relation to polycythaemia vera based on JAK2 V617F mutation status: a prospective study. Lancet 2005; 366: 1945-1953.

63 Kittur J, Knudson RA, Lasho TL, Finke CM, Gangat N, Wolanskyj AP et al. Clinical correlates of JAK2V617F allele burden in essential thrombocythemia. Cancer 2007; 109: 2279-2284.

64 Palandri F, Ottaviani E, Salmi F, Catani L, Polverelli N, Fiacchini M et al. JAK2V617F mutation in essential thrombocythemia: correlation with clinical characteristics, response to therapy and long-term outcome in a cohort of 275 patients. Leuk Lymphoma 2009; 50: 247-253.

65 Thoennissen NH, Krug UO, Lee DHT, Kawamata N, Iwanski GB, Lasho T et al. Prevalence and prognostic impact of allelic imbalances associated with leukemic transformation of Philadelphia chromosome-negative myeloproliferative neoplasms. Blood 2010; 115: 2882-2890.

66 Theocharides A, Boissinot M, Girodon F, Garand R, Teo SS, Lippert E et al. Leukemic blasts in transformed JAK2-V617F-positive myeloproliferative disorders are frequently negative for the JAK2-V617F mutation. Blood 2007; 110: 375-379.

67 Campbell PJ, Baxter EJ, Beer PA, Scott LM, Bench AJ, Huntly BJP et al. Mutation of JAK2 in the myeloproliferative disorders: timing, clonality studies, cytogenetic associations, and role in leukemic transformation. Blood 2006; 108: 3548-3555.

68 Pardanani AD, Levine RL, Lasho T, Pikman Y, Mesa RA, Wadleigh M et al. MPL515 mutations in myeloproliferative and other myeloid disorders: a study of 1182 patients. Blood 2006; 108: 3472-3476.

69 Beer PA, Campbell PJ, Scott LM, Bench AJ, Erber WN, Bareford D et al. MPL mutations in myeloproliferative disorders: analysis of the PT-1 cohort. Blood 2008; 112: 141-149.

70 Vannucchi AM, Antonioli E, Guglielmelli P, Pancrazzi A, Guerini V, Barosi G et al. Characteristics and clinical correlates of MPL 515W > L/K mutation in essential thrombocythemia. Blood 2008; 112: 844-847.

71 Tefferi A, Wassie E, Lasho T, Finke C, Belachew A, Ketterling R et al. Calreticulin mutations and long-term survival in essential thrombocythemia. Leukemia 2014; 28: $2300-2303$.

72 Rotunno G, Mannarelli C, Guglielmelli P, Pacilli A, Pancrazzi A, Fanelli T et al. Impact of calreticulin mutations on clinical and hematological phenotype and outcome in essential thrombocythemia. Blood 2014; 123: 1552-1556.

73 Rumi E, Pietra D, Ferretti V, Klampfl T, Harutyunyan AS, Jelena D et al. JAK2 or CALR mutation status defines subtypes of essential thrombocythemia with substantially different clinical course and outcomes. Blood 2014; 123: 1544-1551.

74 Klampfl T, Gisslinger H, Harutyunyan AS, Nivarthi H, Rumi E, Milosevic JD et al. Somatic mutations of calreticulin in myeloproliferative neoplasms. $N$ Engl J Med 2013; 369: 2379-2390.

75 Nangalia J, Massie CE, Baxter EJ, Nice FL, Gundem G, Wedge DC et al. Somatic CALR mutations in myeloproliferative neoplasms with nonmutated JAK2. N Engl J Med 2013; 369: 2391-2405.

76 Tefferi A, Thiele J, Vannucchi AM, Barbui T. An overview on CALR and CSF3R mutations and a proposal for revision of WHO diagnostic criteria for myeloproliferative neoplasms. Leukemia 2014; 28: 1407-1413.

77 Andrikovics H, Krahling T, Balassa K, Halm G, Bors A, Koszarska M et al. Distinct clinical characteristics of myeloproliferative neoplasms with calreticulin mutations. Haematologica 2014; 99: 1184-1190.

78 Pardanani A, Lasho T, Finke C, Oh ST, Gotlib J, Tefferi A. LNK mutation studies in blast-phase myeloproliferative neoplasms, and in chronic-phase disease with TET2, IDH, JAK2 or MPL mutations. Leukemia 2010; 24: 1713-1718.

79 Jäger R, Gisslinger H, Passamonti F, Rumi E, Berg T, Gisslinger B et al. Deletions of the transcription factor Ikaros in myeloproliferative neoplasms. Leukemia 2010; 24: $1290-1298$.

80 Beer PA, Delhommeau F, LeCouédic JP, Dawson MA, Chen E, Bareford D et al. Two routes to leukemic transformation after a JAK2 mutation-positive myeloproliferative neoplasm. Blood 2010; 115: 2891-2900.

81 Rampal R, Ahn J, Abdel-Wahab O, Nahas M, Wang K, Lipson D et al. Genomic and functional analysis of leukemic transformation of myeloproliferative neoplasms. Proc Natl Acad Sci 2014; 111: E5401-E5410.

82 Harutyunyan A, Klampfl T, Cazzola M, Kralovics R. p53 lesions in leukemic transformation. N Engl J Med 2011; 364: 488-490.

83 Milosevic JD, Puda A, Malcovati L, Berg T, Hofbauer M, Stukalov A et al. Clinical significance of genetic aberrations in secondary acute myeloid leukemia. Am J Hematol 2012; 87: 1010-1016.

84 Klampfl T, Harutyunyan A, Berg T, Gisslinger B, Schalling M, Bagienski K et al. Genome integrity of myeloproliferative neoplasms in chronic phase and during disease progression. Blood 2011; 118: 167-176.

85 Zhang S, Rampal R, Manshouri T, Patel J, Mensah N, Kayserian A et al. Genetic analysis of patients with leukemic transformation of myeloproliferative 
neoplasms shows recurrent SRSF2 mutations that are associated with adverse outcome. Blood 2012; 119: 4480-4485.

86 Ley TJ, Miller C, Ding L, Raphael BJ, Mungall AJ, Robertson AG et al. Genomic and epigenomic landscapes of adult de novo acute myeloid leukemia The Cancer Genome Atlas Research Network. N Engl J Med 2013, 2059-2074.

87 Patel JP, Gönen M, Figueroa ME, Fernandez H, Sun Z, Racevskis J et al. Prognostic relevance of integrated genetic profiling in acute myeloid leukemia. $N$ Engl J Med 2012; 366: 1079-1089.

88 Green A, Beer P. Somatic mutations of IDH1 and IDH2 in the leukemic transformation of myeloproliferative neoplasms. N Engl J Med 2010; 362: 369-370.

89 Abdel-Wahab O, Manshouri T, Patel J, Harris K, Yao J, Hedvat C et al. Genetic analysis of transforming events that convert chronic myeloproliferative neoplasms to leukemias. Cancer Res 2010; 70: 447-452.

90 Tefferi A, Pardanani A, Lim K-H, Abdel-Wahab O, Lasho TL, Patel J et al. TET2 mutations and their clinical correlates in polycythemia vera, essential thrombocythemia and myelofibrosis. Leukemia 2009; 23: 905-911.

91 Figueroa ME, Wahab OA, Lu C, Ward PS, Patel J, Shih A et al. Leukemic IDH1 and IDH2 mutations result in a hypermethylation phenotype, disrupt TET2 function, and impair hematopoietic differentiation. Cancer Cell 2010; 18: 553-567.

92 Tefferi A, Lasho TL, Abdel-Wahab O, Guglielmelli P, Patel J, Caramazza D et al. IDH1 and IDH2 mutation studies in 1473 patients with chronic-, fibrotic- or blastphase essential thrombocythemia, polycythemia vera or myelofibrosis. Leukemia 2010; 24: 1302-1309.

93 Stein BL, Williams DM, O'Keefe C, Rogers O, Ingersoll RG, Spivak JL et al. Disruption of the ASXL1 gene is frequent in primary, post-essential thrombocytosis and post-polycythemia vera myelofibrosis, but not essential thrombocytosis or polycythemia vera: analysis of molecular genetics and clinical phenotypes. Haematologica 2011; 96: 1462-1469.
94 Dingli D, Schwager SM, Mesa RA, Li CY, Dewald GW, Tefferi A. Presence of unfavorable cytogenetic abnormalities is the strongest predictor of poor survival in secondary myelofibrosis. Cancer 2006; 106: 1985-1989.

95 Passamonti $\mathrm{F}$, Rumi $\mathrm{E}$, Arcaini L, Castagnola $\mathrm{C}$, Lunghi $\mathrm{M}$, Bernasconi $\mathrm{P}$ et al. Leukemic transformation of polycythemia vera: a single center study of 23 patients. Cancer 2005; 104: 1032-1036.

96 Swolin B, Rödjer S, Westin J. Therapy-related patterns of cytogenetic abnormalities in acute myeloid leukemia and myelodysplastic syndrome post polycythemia vera. Ann Hematol 2008; 87: 467-474.

97 Gangat N, Tefferi A, Thanarajasingam G, Patnaik M, Schwager S, Ketterling R et al. Cytogenetic abnormalities in essential thrombocythemia: prevalence and prognostic significance. Eur J Haematol 2009; 83: 17-21.

98 Sessarego M, Defferrari R, Dejana AM, Rebuttato AM, Fugazza G, Salvidio E et al. Cytogenetic analysis in essential thrombocythemia at diagnosis and at trans formation. A 12-year study. Cancer Genet Cytogenet 1989; 43: 57-65.

99 Panani AD. Cytogenetic and molecular aspects of Philadelphia negative chronic myeloproliferative disorders: clinical implications. Cancer Lett 2007; 255: 12-25.

100 Panani AD. Cytogenetic findings in untreated patients with essential thrombocythemia. In Vivo 2006; 20: 381-384.

This work is licensed under a Creative Commons Attribution 4.0 International License. The images or other third party material in this article are included in the article's Creative Commons license, unless indicated otherwise in the credit line; if the material is not included under the Creative Commons license, users will need to obtain permission from the license holder to reproduce the material. To view a copy of this license, visit http://creativecommons.org/licenses/ by/4.0/ 